\title{
Carbamazepine-induced angioedema
}

\begin{abstract}
Angioedema is a rare adverse reaction of carbamazepine, which causes localized tissue edema in submucosal and subcutaneous tissue mediated by histamine, serotonin, and kinins (bradykinin). We report a case of 34-year-old female who developed angioedema, $24 \mathrm{~h}$ after administration of carbamazepine for treating bipolar disorder. Patient's symptoms responded rapidly with antihistamine therapy and with the withdrawal of carbamazepine, the offending drug. Carbamazepine-induced angioedema is a life-threatening reaction which requires immediate treatment and monitoring in order to avoid morbidity and mortality.
\end{abstract}

Key words:

Angioedema, antiepileptic drug, carbamazepine, cutaneous reaction

\section{Introduction}

Carbamazepine an iminostilbene anticonvulsant drug commonly used for the treatment of neuralgia, seizure, and bipolar disorder. Cutaneous adverse reactions due to carbamazepine are reported to occur in about 3\% of the population and mostly manifested as mild rash, erythema, petechiae, or exanthematous lesions. ${ }^{[1]}$ Angioedema is an uncommon but serious hypersensitivity drug reaction often associated with angiotensin converting enzyme inhibitors, nonsteroidal anti-inflammatory drugs, and penicillin therapy ${ }^{[2]}$ Prompt recognition and appropriate management of this complication are required to save the life. Although rare, literature review did show few cases of carbamazepine-induced angioedema. ${ }^{[1,3,4]}$ We report here a rare case of carbamazepine therapy associated angioedema.

\section{Case Report}

A 34-year-old female, presented to the dermatology outpatient department of our tertiary care hospital, Puducherry, with generalized facial puffiness and itching all over the body. The patient was a known case of bipolar disorder and hypothyroidism and irregular treatment with tablet lithium $300 \mathrm{mg}$ twice a day and tablet levothyroxine $150 \mu \mathrm{g}$ once a day for the past 5 years. One-week before when the patient developed symptoms of agitation, anxiety, she was advised to continue lithium, levothyroxine regularly, and tablet carbamazepine $100 \mathrm{mg} 3$ times day was added

\begin{tabular}{|l|c|}
\hline \multicolumn{2}{|c|}{ Access this article online } \\
\hline \multirow{2}{*}{$\begin{array}{l}\text { Website: } \\
\text { www.jbclinpharm.org }\end{array}$} & Quick Response Code \\
\hline DOI: & \\
10.4103/0976-0105.189436 & \\
&
\end{tabular}

to her treatment by a private practitioner. Twenty-four hours after the first dose of carbamazepine administration, the patient developed itching all over the body followed by generalized swelling of the face, periorbital area, and lips. The patient had no stridor or difficulty in breathing. The patient also stated that there was no history of allergic conditions, atopic dermatitis, or similar episodes in the past. She was treated with antihistamines (pheniramine maleate and hydroxyzine) and referred to our hospital for further management. On examination, diffuse swelling involving the face, periorbital area, and lips were noted. No other skin, mucocutaneous lesions or organomegaly was noted. Her pharynx was not erythematous and tonsils were normal. The chest X-ray findings were normal. Vitals were stable (pulse rate $82 / \mathrm{min}$, respiratory rate $20 / \mathrm{min}$ and blood pressure $120 / 70 \mathrm{mmHg}$ ). Laboratory investigations showed normal values (total count of 7,900, SGOT $24 \mathrm{IU} / \mathrm{L}$, SGPT $26 \mathrm{IU} / \mathrm{L}$, blood urea $18 \mathrm{mg} / \mathrm{dl}$, and serum creatinine of $0.7 \mathrm{mg} / \mathrm{dl}$ ).

Ansha Subramanian, Mangaiarkkarasi Adhimoolam,
Senthil Gopalakrishnan, Meher Ali Rajamohammed
Department of Pharmacology, Sri Manakula Vinayagar Medical College and
Hospital, Puducherry, India
Address for correspondence:
Dr.Ansha Subramanian,
Department of Pharmacology, Sri Manakula Vinayagar
Medical College and Hospital, Puducherry, India.
E-mail: go2ansha@gmail.com

This is an open access article distributed under the terms of the Creative Commons Attribution-NonCommercial-ShareAlike 3.0 License, which allows others to remix, tweak, and build upon the work non-commercially, as long as the author is credited and the new creations are licensed under the identical terms.

For reprints contact: reprints@medknow.com

How to cite this article: Subramanian A, Adhimoolam M, Gopalakrishnan S, Rajamohammed MA. Carbamazepine-induced angioedema. J Basic Clin Pharma 2016;7:120-2. 
Assessments of the complement system $\left(\mathrm{CH}_{5} \mathrm{O}, \mathrm{C}_{3}\right.$, and $\left.\mathrm{C}_{4}\right)$ and serum carbamazepine level were not done. The offending drug carbamazepine was discontinued and the patient was treated with oral hydroxyzine $25 \mathrm{mg}$ twice a day and topical emollients. Lithium and levothyroxine were continued and risperidone $8 \mathrm{mg}$ once a day was added. The patient showed gradual but steady complete recovery with the treatment and was discharged after 5 days [Figure 1].

\section{Discussion}

Angioedema associated with the use of carbamazepine is a rare but potentially life-threatening reaction. Edema should be managed according to its clinical presentation. Angioedema can be categorized as hereditary or acquired with complications ranging from dysphagia to acute respiratory distress, airway obstruction, and death. ${ }^{[5]}$ In our case, the symptoms were not severe, but developed only after carbamazepine administration and therefore it was possible to comprehend that the angioedema was induced by the same offending drug. The patient improved well with antihistamines without life-saving supportive treatment. However, the patient was not challenged with carbamazepine.

In this case, Naranjo's algorithm was used to determine a plausible reaction due to carbamazepine. ${ }^{[6]}$ The following criteria were considered: There were previous conclusion reports on this reaction $(+1)$, the adverse event appeared after carbamazepine was administered (+2), adverse event improved when carbamazepine was discontinued (+1), adverse event reappeared when carbamazepine was re-administered (o), no alternate causes that could solely have caused the reaction $(+2)$, the reaction reappeared when a placebo was given (o), drug detected in the blood (or their fluids) in a concentration known to be toxic (o), the reaction was more severe when the dose was increased or less severe when the dose was decreased (o), the patient had a similar reaction to carbamazepine in the previous exposure (o), and the adverse event confirmed by objective evidence $(+1)$. Based on the total score of seven, the reaction was categorized

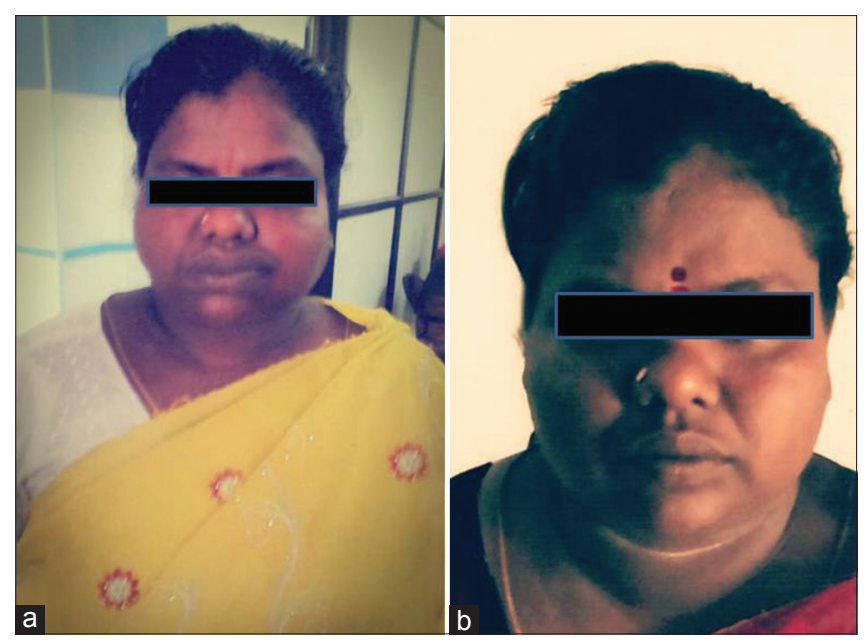

Figure 1: (a) Patient with angioedema showing swelling of both lips, (b) after recovery from angioedema as "probable" reaction to carbamazepine administration. According to the WHO-Uppsala Monitoring Centre causality assessment system, the cutaneous adverse reaction was found to be "probable/likely" reaction to carbamazepine. ${ }^{[7]}$

Angioedema is a vascular reaction involving deep dermis, subcutaneous or submucosal area characterized by asymmetrical nonpitting edema affecting any part of the body mostly confined to head and neck. ${ }^{[8]}$ The pathophysiology is due to loss of integrity of blood vessels leading to plasma extravasation and consequently subcutaneous tissue edema mediated by the involvement of mast cells and in lesser extent basophils, which on activation release histamine from preformed granules. Prostaglandins, leukotrienes (LT) are known to be the other mediators involved. ${ }^{[3]}$ It is postulated that drug-induced angioedema could be immunoglobulin $\mathrm{E}(\mathrm{IgE})$ mediated allergic reaction causing rupture of mast cells and histamine release. It may also due to nonimmunological mediated by interference with arachidonic acid metabolism resulting in LT over production (LTC4, LTD4, and LTE4). The other proposed mechanism is decreased degradation of bradykinin resulting in dilatation of blood vessel and inflammation. ${ }^{[5]}$ In the absence of definite proof regarding the mechanism for the development of angioedema due carbamazepine, we can only speculate that it could be due to IgE-mediated allergic reaction. ${ }^{[3]}$ Due to the potentially life-threatening complication of angioedema and frequent use of anticonvulsants in the treatment of mood disorders, treating physician must be aware of the condition and management. Patients should also be advised to report symptoms suggesting angioedema (swelling of the face, tongue, eyes, lips, or difficulty in breathing) immediately and to stop taking the drug until they have consulted their physician.

\section{Conclusion}

Angioedema is a rare but serious, life-threatening adverse reaction due to carbamazepine, which requires immediate treatment and monitoring by the treating physician in order to avoid further morbidity and mortality.

\section{Declaration of patient consent}

The authors certify that they have obtained all appropriate patient consent forms. In the form the patient(s) has/have given his/her/their consent for his/her/their images and other clinical information to be reported in the journal. The patients understand that their names and initials will not be published and due efforts will be made to conceal their identity, but anonymity cannot be guaranteed.

\section{Financial support and sponsorship} Nil.

\section{Conflicts of interest}

There are no conflicts of interest.

\section{References}

1. Mehta M, Shah J, KhakhkharT, Shah R, Hemavathi KG. Anticonvulsant hypersensitivity syndrome associated with carbamazepine 
administration: Case series. J Pharmacol Pharmacother 2014;5:59-62.

2. Kuriachan S, Amberkar MB, Mohan MK, Shahul HA, Kishore MK. Acebrophylline-induced angioedema. Indian J Pharmacol 2015;47:219-20.

3. Elias A, Madhusoodanan S, Pudukkadan D, Antony JT. Angioedema and maculopapular eruptions associated with carbamazepine administration. CNS Spectr 2006;11:352-4.

4. Gupta SN, Gupta VS. Angioedema caused by carbamazepine or acetazolamide: A single drug solution - An illustrative case report. Neurol Open J 2014;1:20-2.
5. Inomata N. Recent advances in drug-induced angioedema. Allergol Int 2012;61:545-57.

6. Naranjo CA, Busto U, Sellers EM, Sandor P, Ruiz I, Roberts EA, et al. A method for estimating the probability of adverse drug reactions. Clin Pharmacol Ther 1981;30:239-45.

7. The Use of the WHO-UMC System for Standardised Case Causality Assessment. Available from: http://www.who-umc.org/ Graphics/24734.pdf. [Last accessed on 2016 Mar 30].

8. Lee A, Thomson J. Adverse Drug Reactions. $2^{\text {nd }}$ ed. London: Pharmaceutical Press; 2006. p. 131-5.

\section{Author Help: Reference checking facility}

The manuscript system (www.journalonweb.com) allows the authors to check and verify the accuracy and style of references. The tool checks the references with PubMed as per a predefined style. Authors are encouraged to use this facility, before submitting articles to the journal.

- The style as well as bibliographic elements should be $100 \%$ accurate, to help get the references verified from the system. Even a single spelling error or addition of issue number/month of publication will lead to an error when verifying the reference.

- $\quad$ Example of a correct style

Sheahan P, O'leary G, Lee G, Fitzgibbon J. Cystic cervical metastases: Incidence and diagnosis using fine needle aspiration biopsy. Otolaryngol Head Neck Surg 2002;127:294-8.

- Only the references from journals indexed in PubMed will be checked.

- $\quad$ Enter each reference in new line, without a serial number.

- Add up to a maximum of 15 references at a time.

- If the reference is correct for its bibliographic elements and punctuations, it will be shown as CORRECT and a link to the correct article in PubMed will be given.

- If any of the bibliographic elements are missing, incorrect or extra (such as issue number), it will be shown as INCORRECT and link to possible articles in PubMed will be given. 